\section{Cytomegalovirus infection and exchange transfusion}

J O'H Tobin, FRCPATH, and others. . . . . .404

Dietary fibre: search for the facts

C L Copeland. . . . . . . . . . . . . . . . . .404

Health Service administration

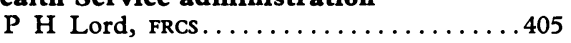

Drugs for rare diseases

R H Johnson, $M D$, and others........405

Management of acute asthma

I Gregg, FRCGP; P S Crosby, MRCPED;

S A Haider, MRCPED ..............405

Epidemiological aspects of choriocarcinoma

M Y Dawood, MD...............406

Medical training in developing countries

A J R Waterston, MB..............406

Hospitals for the developing world

Cicely D Williams, FRCP...........407

Trainer-teaching techniques

C W Savile, MRCGP; R J L Davis, MB;

M G Barley, MB.................407

Medicine and pharmacy

T D Whittet, PHD.................407

Arsine toxicity aboard the Asiafreighter

P J F Henderson................408
Serum creatine phosphokinase and maligmant hyperpyrexia

M A Denborough, FRCP.............408

Oral contraceptives and premenstrual tension

Eleanor Mears, MB................408

Transport of infants for intensive care Sheila R Lewis, MRCP, and Mary A Rossiter, MRCP; Anthea M Blake, SRCN, and E O R Reynolds, FRCP...............408

Clonidine overdose

L M H Wing, $M B$, and others........408

Enteric-coated aspirin overdose and gastric perforation

F J A Bateman, MB ; R J Farrand, MRCPATH . . 409

$A$ safer antidepressant?

C L Brewer, MRCPSYCH. . . . . . . . . . . . 409

Community hospitals: what is their role ?

C A Houlder, MRCP............410

Wanted, a motto

D Kyle, FRCGP...............410

Private practice and the NHS

Mary White, MB; J Neasham, fFARcs. . . . . 410

Junior hospital staff contract

A W L Beatson, MB..............410
Failure of communication

E T Griffiths, MrCGP............410

Industrial action

Hilary J Graver, $M B$, and R J Jarrett, MD;

P M Vicary, MB.................4410

NHS family planning services

W G Mills, FRCOG.............411

Salary increments and anti-inflation policy

H G Saunders, FFarcs ............411

NHS superannuation: lump sum

E Saphier, Mrcs..............411

Pension payment

W J B de Gruchy, MB.

Points from letters Family planning prospects (E C Corderoy); Management of acute asthma (M F Muers); Treatment of "hacks" (Mairead E MacConaill); Battering after strokes (J H Mitchell); Sterilisation: laparoscopy or laparotomy? (W G Dawson); Emergency call system (A Y Finlay); Call for resignation (P W M Copeman); Modifying the reorganisation of the NHS (P J Heath); Junior hospital doctors and the BMA (D I Walker); Junior hospital staff contract (D Peebles Brown; P R S Tasker, and others)...........412
Correspondents are urged to write briefly so that readers may be offered as wide a selection of letters as possible. So many are being received that the omission of some is inevitable. Letters should be signed personally by all their authors.

\section{Cytomegalovirus infection and exchange transfusion}

SIR,-Yeager ${ }^{1}$ has drawn attention to the danger of babies who have acquired cytomegalovirus (CMV) infection from exchange transfusions passing on this agent to their mothers, who, if pregnant, could produce a congenitally infected infant. Two of five non-immune mothers of infected babies studied by her became infected within six months of delivery.

Studies in the special care baby unit of Withington Hospital and its follow-up clinic for "at risk" babies showed that 15 of 51 babies $(29 \%)$ given exchange transfusions in the neonatal period were excreting virus subsequently. In a control group of 42 babies attending the same clinic who had not been subjected to this therapy there were no excreters, and the frequency of CMV isolation from routine hospital admissions in Manchester during the first year of life was only $2 \cdot 2 \%{ }^{2}$

Five mothers of babies found to be excreting CMV following their transfusions, and who had no detectable complement-fixing antibody to CMV, were bled at regular intervals during the period of their babies' virus excretion. Four of these five developed antibody to CMV during this period. Two other mothers with low levels of antibody in blood samples taken a few weeks after their babies were transferred showed more than four-fold rises in titre, indicating either primary infection or reinfection with CMV. None of these women became pregnant during the period of study.

As there was little doubt that these mothers were infected by their exchangetransfused infants, it would seem that this procedure presents a hazard to such mothers who happen to become pregnant within a year of giving birth. It is therefore suggested that the mothers of transfused infants should be tested for antibody to CMV and, if without antibody, should be advised to avoid pregnancy until either the baby has been shown not to have been infected or until it has stopped excreting CMV. Our infected babies usually ceased to excrete CMV after 12-14 months, but one who suffered from the post-transfusion syndrome went on excreting for over $2 \frac{1}{2}$ years.

J O'H TOBIN Public Health Laboratory, Withington Hospital, Withington
Manchester

Paediatric Department

Withington Hospital, Manchester

Yeager, A S, American fournal of Diseases of Cytomegalovirus infection in the North-west of England, Archives of Disease in Childhood
1970, 45, 513.

\section{Dietary fibre: search for the facts}

SIR,-Once again, in a recent BBC TV programme concerning food, a commentator has had no hesitation in linking a list of serious diseases, including cancer of the colon, "with all that lost fibre," singling out white bread critically and claiming that some consumers have to obtain their fibre from a certain (named) proprietary pharmaceutical product. It is important to distinguish between opinion and proved fact, and to this end I would appreciate an opportunity of setting the record straight as far as the milling and baking industries are concerned.

The joint committee which represents the two industries on scientific and medical matters has asked the Chief Medical Officer's Advisory Committee on Medical Aspects of Food Policy (COMA) to undertake an impartial review of the dietary fibre hypothesis. This step was taken with the full agreement of the principal authors of the hypothesis. It is understood that such review will be undertaken by COMA as and when sufficient knowledge has been assembled from research and examination of existing information. A great deal more needs to be learnt about dietary fibre, which is a mixture of a large number of different substances; much of the present work is to isolate those substances and to define their function in the gut. Some of such work is in hand, but more remains to be defined, organised, and undertaken. Considerable time is likely to be involved in so complicated a matter, but it is generally agreed that for the present there is insufficient evidence to require or justify any change in flour milling production. 